\title{
O QUE REVELAM OS ESTUDOS REALIZADOS NO BRASIL SOBRE POLÍTICA DE DIVIDENDOS?
}

\author{
WHAT THE STUDIES CONDUCTED IN BRAZIL REGARDING DIVIDEND POLICY REVEAL \\ ¿OUÉ REVELAN LOS ESTUDIOS REALIZADOS EN BRASIL SOBRE POLITICA DE DIVIDENDOS?
}

\section{RESUMO}

O presente artigo consiste na revisão da literatura sobre política de dividendos no Brasil, com foco nos estudos empíricos realizados no período de 1990 até 2010, que tenham sido objeto de publicação nos principais periódicos nacionais de Administração, Contabilidade e Finanças ou disponíveis em anais dos principais congressos da matéria. A amostra analisada foi composta de 39 trabalhos com variadas metodologias e períodos. Com inspiração no modelo de Harris e Raviv (1991), buscou-se agrupar os trabalhos de acordo com o tipo de modelo, tendo sido identificadas cinco categorias predominantes. Algumas tendências puderam ser percebidas, tais como: relevância da política de dividendos no mercado brasileiro; confirmação da existência de problemas de agência; resultados conflitantes quanto à hipótese da clientela; sinalização e influência dos tributos na definição da política de dividendos; resultados não conflitantes quanto às determinantes da política de dividendos.

PALAVRAS-Chave Dividendos, política de dividendos, proventos, produção bibliográfica, finanças.

Andressa lovine Martins andiov@hotmail.com

Mestranda em Ciências Contábeis e Financeiras pelo Programa de Ciências Contábeis e Atuariais, Pontifícia Universidade Católica de São Paulo - São Paulo - SP, Brasil

Rubens Famá rfama@usp.br

Professor da Faculdade de Economia, Administração e Contabilidade, Universidade de São Paulo, e Professor dos Programas de Mestrado em Administração e Ciências Contábeis e Financeiras, Pontifícia Universidade Católica de São Paulo - São Paulo - SP, Brasil

\begin{abstract}
This paper consists of a review of the literature about dividend policy in Brazil, focusing on the empirical studies conducted from 1990 to 2010 that were published in major Brazilian administration, accounting and finance journals and major conference proceedings on this subject. The analyzed sample comprised 39 studies using various methods and conducted in various periods. Based on the model of Harris and Raviv (1991), this paper grouped studies according to model type, and it found five main categories. We were able to find some tendencies, such as: dividend policy relevance in the Brazilian market; confirmation of existence of agency problems; conflicting findings regarding the clientele hypothesis; tax signaling in, and tax impact on, defining dividend policy; non-conflicting findings regarding key factors of dividend policy..

Keywords Dividends, dividend policy, returns, bibliography, finances.

Resumen El presente artículo consiste en la revisión de la literatura sobre política de dividendos en Brasil, con foco en los estudios empíricos realizados en el período de 1990 a 2010, que hayan sido objeto de publicación en los principales periódicos nacionales de Administración, Contabilidad y Finanzas o que estén disponibles en anales de los principales congresos sobre la materia. La muestra analizada estaba compuesta por 39 trabajos con variadas metodologías y períodos. Con inspiración en el modelo de Harris y Raviv (1991), se buscó agrupar los trabajos de acuerdo con el tipo de modelo, habiendo sido identificadas cinco categorías predominantes. Se logró percibir algunas tendencias, tales como: relevancia de la política de dividendos en el mercado brasileño; confirmación de la existencia de problemas de agencia; resultados conflictivos respecto a la hipótesis de la clientela; señalización e influencia de Ios tributos en la definición de la política de dividendos; resultados no conflictivos respecto a las determinantes de la política de dividendos.

Palabras clave Dividendos, política de dividendos, beneficios, producción bibliográfica, finanzas.
\end{abstract}




\section{INTRODUÇÃo}

O assunto política de dividendos é um dos mais controvertidos no campo das finanças corporativas, desde que o polêmico estudo de Miller e Modigliani (1961) conclui ser esta irrelevante, refutando o pensamento conservador predominante, segundo o qual os investidores prefeririam receber dividendo a ganho de capital, fundamentado, principalmente, nos papéis de Lintner (1956) e Gordon (1959). A partir de então, não houve consenso sobre a sua relevância, tampouco sobre qual seria a política mais adequada.

O Brasil, em especial, possui particularidades que tornam o estudo ainda mais interessante e polêmico. Procianoy (2006) aponta quatro fatores específicos que influenciaram a evolução do tratamento dos dividendos ao longo dos anos. O primeiro aspecto é precedente à queda da inflação, quando o dividendo era visto como algo sem importância, uma vez que o valor monetário dos dividendos definidos em assembleia era corroído pela inflação. O segundo aspecto refere-se ao período de pós-estabilização do processo inflacionário, ocorrido a partir de julho de 1994, quando o investidor passa a perceber a importância dos dividendos. O terceiro aspecto concerne ao crescimento significativo da bolsa de valores, que levou o investidor a priorizar o ganho de capital em detrimento do dividendo. Por fim, o quarto aspecto refere-se à fase em que a governança corporativa passou a ser uma preocupação.

Ainda, do ponto de vista fiscal, o histórico legislativo favorece a avaliação do impacto tributário na política de dividendos da empresa, na medida em que propicia diversos cenários para análise e reflexão. No período de 1989 a 1992, o imposto sobre o lucro líquido (ILL) onerava o lucro da empresa, independentemente da distribuição de dividendos, com alíquota de $8 \%$. Em 1993, os dividendos passaram a ser isentos e, em 1994 e 1995, voltaram a ser tributados pelo imposto de renda, à alíquota de 15\%. Por fim, a partir de 1996, a distribuição de dividendos para qualquer sócio ou acionista, independentemente da nacionalidade, passou a ser isenta do imposto de renda, diferenciando-se da maioria dos países. Acrescente-se a esse histórico a criação dos juros sobre capital próprio (JCP), em vigor a partir de 1996, que, apesar de serem uma das formas de distribuição de resultado, podem ser deduzidos da base de cálculo do imposto de renda e da contribuição social sobre o lucro da companhia pagadora, desde que preenchidos determinados requisitos legais, porém sujeitos ao imposto de renda na fonte à alíquota de
15\% pelo acionista, tendo tratamento tributário distinto para pessoa física, jurídica ou estrangeira. Enquanto em outros países a discussão sobre a remuneração do acionista limita-se à definição entre dividendo e ganho de capital, no Brasil devem-se incluir na avaliação os JCP, o que torna a análise mais complexa. Apenas para exemplificar, a carga tributária total sobre JCP da pessoa jurídica beneficiária pode chegar a 34\% (imposto de renda e contribuição social sobre o lucro) mais 9,65\% de PIS e Cofins.

Conquanto no exterior os estudos sobre política de dividendos estejam se desenvolvendo desde o final da década de 1950, no Brasil as discussões são mais recentes, tendo se destacado a partir da década de 1990, com o processo de estabilidade monetária. Diante desse arcabouço, e especialmente da pertinência do tema e do espaço aberto para a verificação dos seus reflexos no mercado brasileiro, pareceu extremamente conveniente a realização de uma revisão bibliográfica dos estudos já existentes, abrangendo o período de 1990 até 2010, de tal forma a cotejar os trabalhos empíricos realizados com a teoria, seguindo os moldes do artigo de Harris e Raviv (1991). A abrangência do período possibilita incluir não apenas as fases pré e pós-estabilização econômica, mas os períodos com diferentes tratamentos tributários da distribuição de resultados.

Espera-se poder identificar, sumarizar e classificar por categorias os estudos produzidos no Brasil sobre política de dividendos, com foco nos estudos empíricos, comparando os resultados obtidos, relacionando-os com a teoria e buscando avaliar se existe alguma tendência. Afinal, o que revelam os estudos empíricos sobre política de dividendos realizados no Brasil?

\section{Referencial Teórico}

Os precursores da discussão sobre a importância ou relevância da política de dividendos são os clássicos estudos de Lintner (1956) e Gordon (1959), que demonstraram que o retorno ao acionista é menor conforme aumenta a distribuição de dividendos, porque os investidores têm menos certeza de receber o ganho de capital futuro do que os dividendos presentes. $\mathrm{O}$ que tais autores defendem, na verdade, é que o dividendo possui um fator risco menor do que o ganho de capital, uma vez que este é associado a uma data futura e incerta. Tais argumentos ficaram conhecidos como Teoria do Pássaro na Mão. Autores como Brealey \& Myers (1992) denominam essa corrente de pensamento de tradicional ou conservadora, pelo fato de 
privilegiar o recebimento de dividendos em função do menor risco.

Refutando a teoria tradicional, Miller e Modigliani (1961) argumentaram que os investidores podem planejar seus investimentos e, em uma situação de mercado perfeito, assim considerado um mercado sem tributos, com taxas de juros iguais para todos e sem custos de corretagem, a política de dividendos seria indiferente para o acionista. Segundo tais autores, o valor da empresa é determinado apenas pela capacidade de geração de valor e pelo risco do negócio, dependendo somente do lucro produzido pelos seus ativos e não de como esse lucro é repartido entre dividendos e lucros retidos. Trata-se da corrente de pensamento intermediária, para a qual a política de dividendos é irrelevante.

Uma terceira teoria é a da preferência tributária, para a qual, em um mercado em que os dividendos são tributados a uma alíquota maior do que os ganhos de capital, como o americano, o investidor preferirá uma política de dividendos que tenha a menor distribuição possível, uma vez que a carga tributária consumirá parte substancialmente maior do seu rendimento. Essa corrente de pensamento é denominada radical, pois defende a menor distribuição de dividendos e afirma que o aumento do pagamento de dividendos pode provocar a redução do preço das ações. Seus principais expoentes foram Brennan (1970) e Litzenberger e Ramaswamy (1979).

Como desdobramento das teorias clássicas sobre política de dividendos, outras discussões mais abrangentes no campo da teoria de finanças, que também envolvem estrutura de capital e política de dividendos, foram sendo desenvolvidas e aprimoradas, merecendo destaque: teoria de agência; assimetria informacional e efeito clientela.

\section{Teoria de agência}

Em artigo seminal sobre a matéria, Jensen e Meckling (1976) demonstraram matematicamente a existência de custos de agência decorrentes dos conflitos entre acionistas e executivos, bem como entre acionistas e credores. A demonstração de tais autores descortinou os conflitos de interesse entre acionistas e gestores, num contexto de separação entre propriedade e controle, na medida em que o objetivo principal de cada um é maximizar as suas próprias utilidades. Conforme apontado no estudo de Silva (2003), a literatura internacional possui inúmeras evidências de que empresas com fluxo de caixa livre e poucas oportunidades de investimento tendem a incorrer em maiores custos de agência. Dessa forma, o pagamento de dividendos teria o condão de reduzir o conflito de agência, uma vez que diminui os recursos à disposição dos gestores.

De acordo com os estudos brasileiros ora analisados, entre os quais Procianoy (1996), Silva (2004) e Bellato, Silveira e Savoia (2006), enquanto na literatura internacional o maior conflito de agência relatado ocorre entre acionistas e gestores, em função da pulverização da estrutura de propriedade, no Brasil, a alta concentração de controle nas mãos de um único acionista revela como maior conflito aquele entre acionista controlador e minoritário. Este é reforçado pelo fato de haver duas diferentes classes de ações no Brasil, com e sem direito a voto, e pela emissão em grande número de ações sem direito a voto. Assim, grande parte dos acionistas de uma companhia brasileira tem direito à distribuição de resultados, mas não poder para interferir na gestão ou distribuição destes, ficando essa tarefa na mão dos controladores, que interferem na gestão sem ter necessariamente a maioria das ações da empresa, mas apenas das ações votantes.

\section{Assimetria informacional}

Essa hipótese surge diante da inegável constatação de que os administradores detêm mais informações sobre as perspectivas futuras de investimentos e de dividendos que os demais acionistas.

Algumas teorias relacionam a política de dividendos e a de investimentos. A pecking order theory, teoria da hierarquia das fontes, pressupõe que as empresas preferem usar lucros retidos a contrair dívidas e, no caso de a necessidade de investimentos superar tais recursos, preferem emitir títulos de dívidas a emitir ações. Nesse caso, a distribuição de lucros varia positivamente com a lucratividade e negativamente com o investimento. Decorrência disso também é a constatação de que as empresas mais rentáveis são menos endividadas, pois utilizam parte dos lucros retidos nos seus projetos. Por sua vez, mantida a lucratividade constante, empresas com maiores investimentos são mais endividadas.

Segundo a teoria de tradeoff estática, os custos de agência e benefícios fiscais induzem as companhias mais rentáveis a serem mais endividadas. Assim, mantida a lucratividade constante, empresas com maiores oportunidades de investimentos rentáveis pagam mais dividendos e têm menor alavancagem. O motivo da relação positiva entre lucratividade e dividendos, segundo Brito e Silva (2005), seria diminuir o fluxo de caixa livre na mão dos gestores. 
Nesse contexto, surge também a hipótese da sinalização, segundo a qual, dado o descompasso de informações entre Administração e acionistas, os gestores podem usar a estrutura de capital e os dividendos para sinalizar a respeito das perspectivas futuras das empresas. Os estudos baseados nessa hipótese buscam evidenciar se o aumento da distribuição de lucro provoca reação positiva no valor das ações, bem como se sua diminuição tem o efeito contrário.

\section{Efeito clientela}

A hipótese de clientela foi inicialmente apontada por Miller e Modigliani (1961), os quais, após demonstrarem a irrelevância da política de dividendos em um mercado perfeito, introduziram algumas imperfeições do mercado na sua análise. Apontaram, então, a existência de um efeito clientela, que consistiria na preferência dos investidores por determinadas ações com o nível de pagamento de dividendo mais adequado a sua faixa de tributação. Posteriormente, diversos estudos testaram o referido efeito, tendo sido o primeiro o desenvolvido por Elton e Gruber (1970). Tais autores demonstraram empiricamente que, se o dividendo e o ganho de capital forem taxados com alíquotas diferentes, assumindo haver racionalidade dos investidores, haverá preferência pela opção de remuneração em que o tributo seja menor, ou seja, que proporcione maior rendimento líquido. Assim, os tributos teriam importante papel na decisão de distribuição, uma vez que o mercado considera os impostos incorridos na avaliação do preço ex direito da ação.

\section{METODOLOGIA}

A seguir, será apresentada a metodologia utilizada para a seleção e classificação dos artigos.

\section{Amostra e período}

A amostra foi obtida por meio da pesquisa nos principais periódicos e congressos nacionais das áreas de Administração, Contabilidade e Finanças, no período de 1990 a 2010. Os periódicos consultados foram: Rausp, RAE, RAC, BBR, BAR, ReAD, RBFin e RConFin, segundo classificação do Qualis Capes, extrato igual ou superior a B2 em 2008. Os anais pesquisados foram dos seguintes congressos: Encontro da Anpad,
Encontro Brasileiro de Finanças e Congresso USP de Controladoria e Contabilidade. Nos casos de trabalho apresentado em congresso e posteriormente publicado em periódico, foi considerado apenas o último, para não haver duplicidade.

Incluíram-se também dois trabalhos das principais revistas de economia ( $R B E$ e $E E$ ), por terem sido referências em outros trabalhos, que, após pesquisa no site de tais periódicos, se constatou serem os únicos sobre o tema.

A metodologia de seleção de artigos acima permite concluir, de acordo com os preceitos da revisão bibliométrica, que foram reunidos os principais trabalhos sobre política de dividendos publicados no Brasil no período em tela. Segundo Cunha (1985): "Uma lei de concentração e dispersão da literatura científica foi estudada por Bradford em 1934. Segundo esse autor, somente um pequeno número de periódicos (os chamados nucleares ou essenciais) é necessário para fornecer os artigos mais importantes de um assunto".

Após levantamento dos artigos pelo assunto e leitura dos resumos, foram descartados os estudos setoriais, estudo de casos e trabalhos teóricos, bem como aqueles que não guardavam relação direta com o objeto da presente pesquisa.

Assim sendo, a amostra é composta por todos os artigos e trabalhos publicados em anais, das revistas e congressos acima apontados, cujo tema central é política de dividendos, ressalvados os descartes acima mencionados, totalizando 39 estudos, conforme quadros a seguir.

\section{Modelo}

A metodologia empregada seguiu os moldes do artigo de Harris e Raviv (1991), o qual teve como objetivo identificar a literatura sobre estrutura de capital na década de 1980, sintetizando os resultados, relacionando a teoria com os estudos empíricos, estabelecendo relações, identificando vieses em comum entre os trabalhos analisados e classificando-os em modelos.

No presente trabalho, o foco serão os estudos empíricos brasileiros sobre política de dividendos. Dado o fato de que os trabalhos nacionais geralmente baseiam-se em modelos de pesquisa realizadas no exterior, havendo inúmeros modelos metodológicos adotados, optou-se por efetuar as classificações especialmente com base no principal objetivo dos trabalhos brasileiros e não necessariamente nos modelos empíricos estrangeiros seguidos, conforme abaixo: 
- Modelos baseados na teoria de agência. Estudos que procuram identificar fenômenos típicos da teoria no mercado de capitais brasileiros, por meio da política de dividendos. Este grupo inclui os modelos que investigam os reflexos da estrutura de propriedade na política de dividendos.

- Modelos baseados na assimetria informacional. Estudos que partem do pressuposto de que a Administração e os insiders possuem informação privilegiada. Na mesma linha do trabalho paradigma, podem ser subdivididos em duas categorias: interação entre investimento e política de dividendos; dividendos como sinalizadores.

- Modelos baseados na hipótese da clientela. Estudos que buscaram identificar a existência do efeito clientela no mercado brasileiro. Tais estudos foram divididos em duas categorias distintas: estudos de evento focados na data com e data ex dividendo; outros estudos de evento.

- Modelos baseados na influência dos tributos na política de dividendos. Em função das alterações legislativas que impactaram na tributação dos dividendos na década de 1990, inclusive a instituição dos JCP, alguns estudos verificaram a influência dos tributos na política de dividendos.

- Modelos baseados nas determinantes da política de dividendos. Tais modelos empíricos buscam identificar quais fatores têm mais influência na determinação da política de dividendos.

É importante considerar que muitos estudos podem ser enquadrados em mais de uma categoria; eventualmente, na tentativa de identificar um viés de uma teoria, terminam por identificar outro, até pelo fato de as teorias e hipóteses acima se relacionarem frequentemente. Todavia, procurou-se efetuar a classificação analisando-se o trabalho como um todo, seu principal objetivo, e por semelhança aos demais.

\section{RESULTADOS E DISCUSSÕES}

Seguindo a divisão acima, os trabalhos selecionados serão apresentados adiante dentro de cada grupo em que foram classificados.

\begin{tabular}{|c|c|c|c|}
\hline \multicolumn{4}{|c|}{$\begin{array}{l}\text { Quadro } 1 \text { - Relação de trabalhos selecionados por revista e pontuação no Qualis/Capes } \\
\text { categoria Administração e Ciências Contábeis }\end{array}$} \\
\hline Revistas & Abreviação & Pontuação & Trabalhos \\
\hline Brazilian Business Review (Fucape) & $B B R$ & B2 & 1 \\
\hline Estudos Econômicos (USP) & $E E$ & B1 & 1 \\
\hline RAE-eletrônica (FGV) & RAE-e & B1 & 1 \\
\hline RAE-Revista de Administração de Empresas (FGV) & $R A E$ & B1 & 1 \\
\hline Revista de Administração (USP) & Rausp & B2 & 3 \\
\hline Revista Brasileira de Economia (FGV) & $R B E$ & A2 & 1 \\
\hline Revista Brasileira de Finanças (SBFin) & RBFin & B1 & 1 \\
\hline Revista de Contabilidade e Finanças (USP) & RConFin & B1 & 5 \\
\hline Total de trabalhos & & & 14 \\
\hline
\end{tabular}

\section{Quadro 2 - Relação de trabalhos selecionados por congresso}

\begin{tabular}{|l|c|c|}
\hline \multicolumn{1}{|c|}{ Congressos } & Abreviação & Trabalhos \\
\hline Congresso USP de Controladoria e Contabilidade & Congresso USP & 5 \\
\hline Encontro da Associação Nacional de Pós-Graduação e Pesquisa em Administração & Enanpad & 15 \\
\hline Encontro Nacional da Sociedade Brasileira de Finanças & EnSBFin \\
\hline Total geral & 5 \\
\hline
\end{tabular}




\section{Modelos baseados na teoria de agência}

A amostra dos trabalhos cujos objetivos estavam relacionados a questões da teoria de agência foi dividida em dois grupos. No Quadro 3, foram agrupados os trabalhos que visaram a identificar fenômenos da teoria de agência no mercado de capitais brasileiro. Trata-se de trabalhos com abordagens bem distintas, mas que buscam o mesmo objetivo: demonstrar como os custos de agência influenciam a política de dividendos e vice-versa.

No Quadro 4, estão relacionados os trabalhos focados na análise da relação entre a estrutura de propriedade e a política de dividendos.

Os estudos empíricos brasileiros cujo tema central é o grau de interferência do conflito de agência na política de dividendos partem do pressuposto de que, se tal fenômeno está presente no mercado brasileiro, onde grande parte dos acionistas com direito a dividendos (ou JCP) não tem poder de controle ou qualquer interferência na gestão, a tendência será o acionista controlador reter a maior quantidade de recursos na companhia, em detrimento da distribuição dos resultados. Isso vai contra a maximização da riqueza dos acionistas, especialmente em se tratando de um ambiente em que os dividendos não são tributados e o ganho de capital sim, situação verificada na grande maioria dos anos abarcados pela presente pesquisa.

Tanto os modelos que partiram da análise do comportamento dos gestores como aqueles que investigaram aspectos da estrutura de propriedade confirmam a existência de fenômenos decorrentes da relação de agência no mercado de capitais brasileiro, evidenciando o conflito existente entre acionistas controladores e minoritários.

\section{Modelos baseados na assimetria de informações}

Os modelos classificados nessa categoria foram subdivididos em: (i) interação entre investimento e política de dividendos; (ii) dividendos como sinalizadores.

\section{Interação entre investimentos e dividendos}

Trata-se de modelos que buscam relacionar a política de dividendos com investimentos, merecendo destaque aqueles embasados nas teorias de estrutura de capital, tais como trade off estática e pecking order, teorias estas já tratadas anteriormente. No Quadro 5, abaixo, estão resumidos os principais trabalhos com essa abordagem.

\section{Quadro 3 - Trabalhos que visam a identificar relação entre teoria de agência e política de dividendos}

\begin{tabular}{|c|c|}
\hline $\begin{array}{c}\text { Autor/Periodo da } \\
\text { amostra* }^{*}\end{array}$ & Metodologia/Principais conclusões \\
\hline $\begin{array}{l}\text { - } \text { Procianoy (1996) } \\
\text { - } 1987 \text { a } 1992\end{array}$ & $\begin{array}{l}\text { Verificou se houve aumento do índice de payout no período em que dividendos fossem isentos e ganho de } \\
\text { capital tributado (1990-1992). A amostra foi segmentada em três (1987-1988: dividendos tributados; 1989: } \\
\text { neutro; 1990- 1992: dividendos isentos). Conclusões: } \\
\text { - Tributação influenciou pagamento de dividendos; } \\
\text { - Houve aumento do payout após } 1990 \text { e inexplicável diminuição em 1992; } \\
\text { - Resultados confirmam fenômeno da teoria de agência segundo o qual, diante de um cenário de } \\
\text { dificuldade, os gestores utilizam os dividendos para sinalizar ao mercado que os tempos ruins são } \\
\text { passageiros. }\end{array}$ \\
\hline $\begin{array}{l}\text { - } \quad \text { Silva (2003) } \\
\text { - } 1998 \text { a } 2001\end{array}$ & $\begin{array}{l}\text { Analisou a influência dos custos de agência na política de dividendos das empresas brasileiras, por meio de } \\
\text { regressões em pooled. Os resultados indicaram que as variáveis de maior influência na política de dividendos } \\
\text { foram lucros correntes e dividendos do período anterior. Quanto aos custos de agência, parecem ter influência } \\
\text { sobre os dividendos. Suporte à hipótese de que existe forte e negativa relação entre dividendos e custos de } \\
\text { monitoramento externo. }\end{array}$ \\
\hline $\begin{array}{l}\text { - Gonzaga e Costa (2009) } \\
\text { - } 1995 \text { a } 2006\end{array}$ & $\begin{array}{l}\text { Testaram a existência de relação entre conservadorismo contábil e conflito sobre política de dividendos, } \\
\text { pressupondo que informações contábeis mais conservadoras podem reduzir o pagamento de dividendos } \\
\text { excessivos, diminuindo conflito de interesses entre acionista controlador e acionistas minoritários. } \\
\text { Encontraram indícios da pertinência da relação. }\end{array}$ \\
\hline
\end{tabular}

* As amostras são compostas por empresas com ações negociadas na Bovespa. 


\section{Dividendos como sinalizadores}

Parcela significativa dos estudos analisados tem o objetivo de averiguar se existe uma relação entre o pagamento dos dividendos e a lucratividade futura. Os quadros a seguir foram divididos em duas partes:
Quadro 6 - estudos que confirmam efeito de sinalização dos dividendos e Quadro 7 - estudos que não confirmam sinalização.

Apenas três trabalhos confirmam que dividendos sinalizam retornos futuros positivos.

\section{Quadro 4 - Trabalhos que avaliam a relação entre política de dividendos e estrutura de propriedade}

\begin{tabular}{|c|c|}
\hline $\begin{array}{c}\text { Autor/Periodo da } \\
\text { amostra* }^{*}\end{array}$ & Metodologia/Principais conclusões \\
\hline $\begin{array}{l}\text { - } \quad \text { Silva (2004) } \\
\text { - } \quad \text { Ano de } 2000\end{array}$ & $\begin{array}{l}\text { Analisou os efeitos da estrutura de controle e propriedade no valor de mercado das ações, estrutura de capital } \\
\text { e política de dividendos, buscando avaliar, entre outros aspectos, se existe relação entre concentração de } \\
\text { controle e pagamento de dividendos, por meio do índice de payout. As principais conclusões foram: } \\
\text { - Empresas com grande concentração de direitos a voto na mão de controlador têm baixo payout, } \\
\text { - Empresas com alta concentração de fluxo de caixa na mão do controlador têm alto payout, } \\
\text { - Empresas com grande separação entre direitos a voto e fluxo de caixa nas mãos do controlador têm } \\
\text { - } \text { menor payout, }\end{array}$ \\
\hline $\begin{array}{l}\text { - Bellato, Silveira e } \\
\text { Savoia (2006) } \\
\text { - } 1998 \text { a } 2003\end{array}$ & $\begin{array}{l}\text { Investigaram a existência de uma relação entre o excesso de poder de voto do controlador e a taxa de } \\
\text { pagamento de dividendos. Os resultados estão em linha com os de Silva (2004), dando conta de que: } \\
\text { - Empresas com grande concentração de direitos a voto na mão de controlador têm menor payout, } \\
\text { - Empresas com grande separação entre direitos a voto e fluxo de caixa nas mãos do controlador têm } \\
\text { menor payout. }\end{array}$ \\
\hline
\end{tabular}

*As amostras são compostas por empresas com ações negociadas na Bovespa.

\section{Quadro 5 - Trabalhos baseados na relação entre política de dividendos e de investimentos}

\section{Autor/Periodo da}

amostra*

- Freitas e Costa (1990)

- 1978 a 1987

- Brito e Silva (2005)

- 1995 a 2001

- Loss e Sarlo Neto (2006)

- 1998 a 2002

- Futuema, Basso e Kayo (2009)

- 1995 a 2004

\section{Metodologia/Principais conclusões}

Testaram a relação entre lucro líquido, investimentos e dividendos pagos, utilizando dois modelos: modelo de dividendos, derivado de Lintner (1956), segundo o qual o dividendo proposto é função do dividendo anterior e do lucro atual, acrescentando a variável investimento; e modelo de investimento, incorporando outras variáveis tais como vendas, ativo total, autofinanciamento e taxa de crescimento. Resultados indicam que o lucro líquido foi a variável mais relevante para política de dividendos, bem como que a decisão de investimento independe de tal política.

Testaram as previsões das teorias trade off e pecking-order, seguindo o modelo de Fama e French (2002 apud Brito e Silva, 2005). Os resultados confirmam previsão comum de trade-off e pecking order, segundo a qual a lucratividade é o fator de maior peso para o pagamento de dividendos.

Verificaram a inter-relação entre as variáveis: dividendos e investimentos, por meio de regressões em pooled para setores específicos. As conclusões foram que uma variável não explica a outra.

Testaram as previsões das teorias trade off e pecking-order, como Brito e Silva (2005), tendo encontrado resultados semelhantes. Identificaram a lucratividade como variável de maior peso na política de dividendos. Não encontradas evidências de que há ajuste nas distribuições de lucro para absorver as variações de curto prazo do investimento. Apoio à teoria de que os dividendos possuem sinalização implícita. Confirmação da teoria de pecking order no sentido de que os dividendos são fixos e eventuais variações no investimento são absorvidas pelo endividamento.

* As amostras são compostas por empresas com ações negociadas na Bovespa. 


\section{Quadro 6 - Estudos que confirmam hipótese da sinalização}

Autor/Período da amostra*

\section{Dividendos sinalizam bons retornos futuros:}

- Novis Neto e Saito (2003)

- 1998 a 2000

- Kuronuma, Lucchesi e Famá (2004)

- 2000 a 2003

- Nossa, Nossa e Teixeira (2007)

- 1995 a 2004

\section{Metodologia/Principais conclusões}

Buscaram evidências da existência de retornos anormais no período pós-pagamento de dividendos (considerado um período de 90 dias) sem foco em imperfeições de mercado. Encontraram uma relação direta entre dividend yield e retorno anormal acumulado no período pós-pagamento de dividendos, ou seja, quanto maior 0 yield, maior o retorno acumulado. Resultados confirmam que dividendos sinalizam ao mercado sobre a situação da companhia.

Como no trabalho acima, os autores buscaram evidenciar a existência de retornos anormais no período pós-pagamento de dividendos (considerado um período de 60 dias) sem foco em imperfeições de mercado. Os resultados encontrados estão em linha com os de Novis Neto e Saito (2003), ou seja, quanto maior 0 dividend yield, maior o retorno acumulado da ação.

Nesse caso, o objetivo dos autores foi averiguar se as empresas que pagaram dividendos foram mais eficientes, considerando a eficiência por meio do retorno sobre ativo (ROA). 0 método estatístico utilizado foi regressão múltipla. A conclusão foi que as empresas que pagaram dividendos foram mais eficientes.

Ações com baixa distribuição têm retorno maior:

- Corso, Kassai e Lima (2010)

- 1995 a 2008

${ }^{*}$ As amostras são compostas por empresas com ações negociadas na Bovespa.
Investigaram a relação entre a distribuição de dividendos e JCP com o retorno das ações, por meio da técnica multivariada da análise de correspondência em painel. Observaram uma relação entre as variáveis, destacando-se que ações com baixa distribuição de dividendos e JCP apresentam retorno alto, ao passo que ações com alta distribuição apresentam retorno baixo.

\section{Quadro 7 - Estudos que não confirmam hipótese da sinalização}

\section{Autor/Período da} amostra*

- Figueiredo (2002)

- 1986 a 2000

- Bueno (2002)

- 1994 a 1999

- Freire e Lima (2005)

- Período de 2000 a 2003

- Castro e Freire (2005)

- 1996 a 2002

- Freire e outros (2005)

- 1995 a 2001

\section{Metodologia/Principais conclusões}

Objetivou testar a hipótese do conteúdo informativo no Brasil para verificar se alterações nos dividendos fornecem informações a respeito da lucratividade futura das empresas, por meio de regressões, da correlação entre a taxa de alteração dos dividendos por ação no ano zero, e as mudanças dos lucros nos anos zero, um e dois, divididas pelo valor de mercado da ação no início do ano de alteração do dividendo. Resultados não confirmam a hipótese.

Verificou a relação do dividend yield e taxa de retorno das ações, buscou confirmar a existência de uma estratégia baseada em dividend yields históricos para bater o mercado. Não encontradas evidências empíricas que suportem a referida estratégia.

Buscaram evidências empíricas em relação ao comportamento dos dividendos e os lucros anormais. Verificou-se a inexistência de relação entre 0 dividend yield e o lucro anormal.

Buscaram evidências empíricas da relação entre lucros anormais e dividendos através da aplicação de análise de regressão, tendo como variável dependente os lucros anormais e, como independente os dividendos (dividendo por ação, índice de payout e dividend yield). Não encontraram relação entre lucros anormais e dividendos, pois nem todos os índices de dividendos utilizados tiveram poder explicativo.

Avaliaram se existe relação entre a média de distribuição de dividendos e a média dos lucros anormais na amostra utilizada. 0 resultado obtido por meio da aplicação de regressão linear simples e estatística descritiva foi inconclusivo em função da baixa relevância do coeficiente de inclinação. 
(conclusão)

- Fiorati, Garcia e Tambosi Filho (2007)

- 1999 a 2004

- Decourt, Procianoy e Pietro Neto (2007)

- 1997 a 2005
Testaram a hipótese do conteúdo informativo no Brasil para verificar se alterações nos dividendos fornecem informações a respeito da lucratividade futura das empresas. A metodologia utilizada foi semelhante à de Figueiredo (2002). Resultados não confirmam a hipótese testada.

Analisaram 432 eventos de pagamento de dividendos de empresas que compuseram a amostra. Resultados contrariam hipótese de que os dividendos sinalizam aumento de lucros futuros. No estudo, foi observado que a redução de payout é um indicativo de crescimento de resultado futuro. Segundo os autores, a redução do payout geralmente decorre de aumento do lucro líquido, o que significa que 0 aumento de lucro não gera maior distribuição. Fenômeno atribuído ao conflito de agência, uma vez que o controlador não tem direito aos recursos totais da empresa, mas a apenas uma parcela dos dividendos.

*As amostras são compostas por empresas com ações negociadas na Bovespa.

\section{Quadro 8 - Estudos que testaram comportamento das ações na data com e ex-dividendo}

Autor/Período da amostra* Metodologia/Principais conclusões

\section{Não confirmam efeito clientela e aconselham estratégia de comprar ações na data com e vender na data ex:}

- Procianoy e Verdi (2003)

- 1989 a 1993

- Santos e outros (2004)

- 1996 a 2002

- Procianoy e Verdi (2009)

- 1996 a 2000
Testaram o efeito clientela no mercado brasileiro por meio do estudo de eventos. Apenas $5 \%$ das ações comportaram-se conforme o esperado no primeiro dia após o pagamento dos dividendos, e $47 \%$ dos casos apresentaram um resultado surpreendente, em que o preço da ação no primeiro dia ex-dividend foi maior do que na data em que a ação tinha direito a receber dividendos. Isso revela comportamento irracional do mercado, já que os investidores estariam pagando mais por ações sem dividendos do que com dividendos.

Buscaram confirmar se, no mercado brasileiro, o comportamento das ações no dia ex dividendo seria semelhante ao observado por Elton e Gruber (1970), ou seja, se a redução no seu preço na data ex se deve ao efeito dividendos pagos acrescido dos tributos. As evidências empíricas demonstram que a queda do preço das ações nos dias ex dividendos e ex JCP não decorrem exclusivamente da tributação, mas sim da ineficiência de mercado.

Continuidade do estudo de 2003, estendendo suas análises para o período de 1996 a 2000. Resultados semelhantes aos da pesquisa anterior. Para o teste do efeito clientela, foi seguida a mesma metodologia de 2003, porém foram incluídas variáveis exploratórias. Os pagamentos de dividendos também foram divididos em dois grupos: dividendos pagos quando anunciados em reunião de Conselho de Administração (RCA) e quando anunciados pela assembleia. 0 s resultados contrariam 0 efeito clientela e confirmam a teoria da sinalização, uma vez detectados retornos anormais nos dias próximos ao pagamento de dividendos, quando anunciados por meio de RCA.

Não confirmam efeito clientela e não aconselham estratégia de comprar ações na data com e vender na data eX:

Analisaram os efeitos de curto prazo com base em uma estratégia simplificada, na qual o investidor adquire

- Perobelli e Santos (2006)

- Ações do Índice Brasil no período de 1996 a 2005

- Perobelli, Zanini e Santos (2009)

- Ações do Índice Brasil no período de 1996 a 2005 a ação na última data com direito ao recebimento dos proventos e vende a ação na primeira data ex direito, recebendo o provento referente e podendo incorrer em perdas ou ganhos de capital. Após a aplicação de métodos de estatística descritiva, concluiu-se haver indicativo de que a estratégia testada não tem sido vantajosa. Porém, para confirmar os resultados obtidos, seria necessário 0 aperfeiçoamento do estudo, por meio da análise de eventos e inclusão de novas variáveis.

Deram continuidade ao estudo de Perobelli e Santos (2006), segmentando a amostra em duas: empresas maduras e em expansão. Os resultados de regressão indicaram que os retornos da estratégia de curto prazo para a amostra total foram negativos em cerca de $3 \%$ do período estudado. Se a empresa distribuísse proventos, haveria ainda uma perda média de capital de cerca de $1,57 \%$ para cada $1 \%$ de yield. Esse valor extrapola muito a faixa máxima prevista pelo modelo de Elton e Gruber (1970) e revela que a perda média de capital no período foi bastante superior ao ganho obtido, ou seja, existe uma queda no preço das ações na data ex, que não decorre exclusivamente do efeito tributário e torna a estratégia de comprar ações na data com e vender na data ex ruim.

* As amostras são compostas por empresas com ações negociadas na Bovespa. 


\section{Modelos baseados na hipótese da clientela}

Classificaram-se os artigos nos seguintes grupos: (i) estudos de eventos que testaram o comportamento das ações nos dias com e ex dividendos, geralmente partindo do modelo empírico de Elton e Gruber (1970), que concluíram que as diferentes alíquotas de impostos levam os investidores a descontar o valor tributado no pagamento de dividendos em relação aos ganhos de capital (Quadro 8); (ii) estudo de eventos que testaram efeito clientela por meio de uma janela maior ou não limitada à data com e data ex (Quadro 9).

Como se vê, os resultados apresentados no Quadro 8 acima são conflitantes quanto à identificação do efeito clientela, bem como quanto à estratégia de compra de ações na última data com e venda na data $e x$.

No Quadro 9, estão relacionados os estudos que também testaram o efeito clientela por meio da análise de eventos, mas não focados exclusivamente na data com e data ex dividendo.

\section{Modelos baseados na influência dos tributos na política de dividendos}

No Quadro 10, estão agrupados os trabalhos que buscaram a evidência do impacto tributário na política de dividendos e na formação do preço das ações. Ramos (1997) e Correia e Amaral (2002) seguiram a metodologia de Litzenberger e Ramaswamy (1979), que, segundo Ramos (1997, p. 8), no intuito de encontrar alguma evidência do efeito dos impostos e dividendos na formação do preço das ações, aperfeiçoaram o modelo ampliado do CAPM de Brennan (1970). O modelo estabelece que, numa relação de equilíbrio, o retorno líquido esperado de uma ação é linearmente relacionado com o risco sistemático e a relação dividendo-preço. Paiva e Lima (2001) não se basearam em nenhum modelo específico, tendo utilizado teste de hipóteses por meio de diferença entre médias e variância entre dois critérios, e Brito, Lima e Silva (2009) estruturaram seu trabalho como o de Fama e French (2002).

\section{Quadro 9 - Outros estudos de eventos}

\section{Autor/Período da} amostra*

\section{Confirmam efeito clientela:}

- Firmino e outros (2003)

- 2002 (ações do lbovespa)

- Procianoy e Kwitko (2007)

- 1996 a 2004 (empresas brasileiras que possuem ADRs tipos II e III listadas na NYSE)

\section{Metodologia/Principais conclusões}

Estudo do evento anúncio do pagamento de dividendos ou JCP. Os retornos observados foram os obtidos em torno de 120 dias do evento. A amostra foi segmentada em dois grupos: maiores e menores yields. Não foram identificados retornos anormais, o que corrobora a hipótese de mercado eficiente. Porém, verificaram retornos anormais sistematicamente positivos no grupo de ações cujo dividend yield era superior à mediana, o que indica a preferência dos investidores por ações com política de dividendos mais agressivas.

Analisaram o comportamento das ações de empresas brasileiras e de suas respectivas ADRs listadas na New York Stock Exchange (NYSE), em períodos próximos ao $1^{\circ}$ dia ex-dividend, para avaliar se a diferença de tributação a que esses ativos estão submetidos influencia o seu desempenho. Avaliaram também a possibilidade de ocorrência de arbitragem entre os dois papéis ao longo do período. Resultados indicam que os investidores não estão obtendo lucros por meio de arbitragem, bem como têm preferido comprar ações a ADRs nos períodos anteriores à data ex, 0 que se atribui ao fato de os dividendos no Brasil não serem tributados. Já na data do evento, essa tendência se reverte, o que foi interpretado como uma possível interferência dos arbitradores. Resultados contrariam a hipótese de mercado eficiente.

\section{Não confirmam efeito clientela:}

- Firmino, Santos e Matsumoto (2004)

- 1996 a 2002 (ações negociadas na Bovespa)
Verificaram se há preferência no mercado brasileiro por ações que pagam maiores dividendos ou juros sobre capital próprio, por meio de estudo de evento, adaptada de Firmino e outros (2003), com uma janela de 120 dias antes e depois do anúncio de pagamento de dividendos, e a mesma segmentação em ações de maior e menor yield. A conclusão foi que, embora 0 anúncio do pagamento de dividendos ou JCP sinalize um sobrepreço em torno da data do anúncio, não acarreta retorno anormal. Não foi possível identificar se há preferência do investidor por ações de maiores dividendos.

${ }^{\star}$ As amostras são compostas por empresas com ações negociadas na Bovespa. 
Com exceção do artigo de Paiva e Lima (2001), ficou evidenciado que a tributação é fator importante tanto para a política de dividendos como no retorno das ações.

\section{Modelo baseado na investigação das determinantes da política de dividendos e JCP}

Os trabalhos classificados nesse grupo possuem metodologias bem distintas, porém todos visam a identificar quais são os fatores de maior peso na determinação da política de dividendos e distribuição de JCP. Segue, no Quadro 11, comparativo da metodologia aplicada e, no Quadro 12, resumo das tendências predominantes.

\section{CONSIDERAÇÕES FINAIS}

O objetivo do presente trabalho foi identificar a literatura sobre política de dividendos no Brasil no período de 1990 a 2010, sintetizando os resultados, relacionando a teoria com os estudos empíricos realizados no mesmo período, estabelecendo relações e identificando vieses em comum entre os resultados analisados.

\section{Quadro 10 - Estudos que buscaram evidência do impacto tributário nos dividendos e/ou no retorno das ações}

\section{Autor/Período da amostra* $^{*}$ \\ Metodologia/Principais conclusões}

\section{Tributação influencia política de dividendos e/ou retornos das ações:}

- Ramos (1997)

- 1988 a 1993

Objetivou identificar se, quando a tributação dos dividendos era maior (1988-1989), os investidores exigiam retornos mais elevados e, após redução da tributação dos dividendos (1990-1993), os investidores passaram a aceitar retornos menores. Para tanto, a amostra foi segmentada nesses dois períodos. Confirmada a hipótese de que os investidores exigem retornos maiores para ações que distribuem mais dividendos quando estes são tributados a alíquotas maiores e aceitam retornos menores quando a tributação é menor.

Verificaram se o retorno das ações pode ser explicado não apenas pelo fator risco sistemático como pressupõe o modelo CAPM, mas também pela variável rendimento em dividendos. A amostra foi segmentada

- Correia e Amaral (2002) em dois períodos: 1994 e 1995 (dividendos tributados) e 1996 a 2000 (dividendos isentos). Conclusão: os

- 1994 a 2000 dividendos também contribuem para a rentabilidade das ações. Resultados corroboram os de Ramos (1997), são exigidos retornos maiores para ações que distribuem mais dividendos quando estes são tributados a alíquotas maiores e retornos menores quando a tributação é menor.

- Brito, Lima e Silva (2009)

Buscaram as razões pelas quais houve um incremento na remuneração dos acionistas no Brasil: teria sido devido às mudanças nas características das empresas brasileiras ou devido às alterações tributárias? A amostra foi segmentada em dois períodos: 1991 a 1995 (dividendos tributados) e 1996 a 2003 (dividendos isentos). Conclusão: a redução tributária foi fator determinante para 0 aumento da distribuição direta de resultados no Brasil.

\section{Tributação não influencia política de dividendos:}

Objetivaram verificar se as alterações tributárias ocorridas no período, ou seja: 1987-1988: dividendos

- Poli e Procianoy (1994)

- 1987 a 1991 sujeitos ao IR; 1989: neutro; 1990-1991: dividendos isentos de IR, tiveram o condão de modificar a política de dividendos, por meio do aumento nos índices de payout. Conclusão: não foi possível afirmar que a mudança na tributação influenciou a política de dividendos das empresas estudadas.

Objetivaram obter evidência empírica da influência da tributação e dos juros sobre capital próprio na política de dividendos das empresas, por meio do estudo do comportamento dos níveis de distribuição de dividendos das companhias. Um dos testes realizados foi do nível de payout em 1995 e a partir de 1996, quando foram instituídos os juros sobre capital próprio e os dividendos tornaram-se isentos. Também foram segmentadas as amostras das empresas que pagaram e que não pagaram JCP no período posterior a 1996. Os resultados encontrados não permitiram concluir que as alterações tributárias provocaram mudanças significativas na política de dividendos.

*As amostras são compostas por empresas com ações negociadas na Bovespa. 
Os trabalhos selecionados foram divididos em cinco categorias, a saber: 1) modelos baseados na teoria de agência; 2) modelos baseados na assimetria informacional: a) interação entre investimento e política de dividendos e b) dividendos como sinalizadores; 3) modelos baseados na hipótese da clientela; 4) modelos baseados na influência dos tributos na política de dividendos; 5) modelos baseados nas determinantes da política de dividendos. De modo geral, revelou-se a relevância da política de dividendos.

Cinco trabalhos foram considerados nos modelos baseados na teoria de agência. Todos reforçam a existência de conflitos entre acionistas controladores e minoritários no mercado brasileiro. Silva (2004) e Bellato, Silveira e Savoia (2006) apontam que quanto menor o direito dos acionistas administradores aos dividendos, menor é o pagamento de dividendos e maior é o interesse em manter os recursos na empresa para sua administração, o que está de acordo com a teoria e a literatura internacional sobre agência e estrutura de propriedade da empresa.

Quatro estudos testaram a relação entre dividendos e investimentos, merecendo destaque a conclusão de que a lucratividade é o fator de maior peso no pagamento de dividendos, conforme três estudos apontados no Quadro 5. Essa constatação também se destacou no trabalho de Silva (2003) e nos estudos que investigaram as determinantes de política de dividendos. A relação entre dividendos e investimentos revelou-se fraca, valendo ressaltar o reduzido número de estudos nesse sentido.

Quanto aos inúmeros estudos que visaram a identificar se os dividendos sinalizam bons resultados futuros, apenas três concluíram que sim. Corso, Kassai e Lima (2010) identificaram uma relação inversa entre distribuição de resultados na forma de dividendos ou

\section{Quadro 11 - Relação de trabalhos e metodologia sobre aspectos determinantes da política de dividendos}

\begin{tabular}{|l|l|r|}
\hline \multicolumn{1}{|c|}{ Artigo } & \multicolumn{1}{c|}{ Metodologia } & \multicolumn{1}{c|}{ Período } \\
\hline Heineberg e Procianoy (2003) & Regressão dados em painel & 1994 a 2000 \\
\hline Iquiapaza, Barbosa e Bressan (2005) & Regressão dados em painel e cointegração & 1986 a 2003 \\
\hline Iquiapaza, Lamounier e Amaral (2006) & Médias de variáveis & 1998 a 2004 \\
\hline Ferreira Junior, Nakamura e Martin (2007) & Regressão linear múltipla & 1997 a 2004 \\
\hline Decourt e Procianoy (2009) & Pesquisa de campo & 2009 \\
\hline Mota e Eid Junior (2010) & Regressões tobit e logit & 2000 a 2005 \\
\hline
\end{tabular}

\section{Quadro 12 - Modelos baseados nos aspectos determinantes da política de dividendos}

Influenciam positivamente pagamento de dividendos:

- Lucro líquido

- Maior porte da empresa

- Fluxo de caixa

- Menor endividamento
Heineberg e Procianoy (2003), Decourt e Procianoy (2009)

Iquiapaza, Barbosa e Bressan (2005), Iquiapaza, Lamounier e Amaral (2006), Ferreira Junior, Nakamura e Martin (2007), Mota e Eid Junior (2010)

Iquiapaza, Lamounier e Amaral (2006), Decourt e Procianoy (2009), Mota e Eid Junior (2010)

Iquiapaza, Barbosa e Bressan (2005), Mota e Eid Junior (2010)

Influenciam negativamente:

- Oportunidades de crescimento

- Maior concentração de propriedade do acionista controlador
Iquiapaza, Lamounier e Amaral (2006), Ferreira Junior, Nakamura e Martin (2007)

Iquiapaza, Lamounier e Amaral (2006), Mota e Eid Junior (2010)

* As amostras são compostas por empresas com ações negociadas na Bovespa. 
JCP e retorno das ações. Por outro lado, oito estudos indicam que a distribuição de dividendos não sinaliza lucratividade futura ou que não foi possível identificar essa relação.

No tocante à hipótese da clientela, na qual foram classificados oito trabalhos, há resultados conflitantes, o que leva a se supor que ou os métodos aplicados precisam ser aperfeiçoados ou o mercado brasileiro não segue a mesma lógica racional demonstrada pela teoria.

Cinco estudos foram incluídos no modelo influência da tributação na política de dividendos. Enquanto três confirmaram tal influência, dois estudos não conseguiram confirmá-la. Esses resultados, aliados aos encontrados no modelo hipótese da clientela, que tem como pressuposto a preferência do investidor pela forma de distribuição menos tributada, indicam que tanto o acionista minoritário quanto os controladores e gestores não estão alinhados sobre a melhor política de distribuição de resultados no Brasil do ponto de vista tributário. Isso provavelmente se deve à complexidade do sistema tributário brasileiro, questão pouco analisada nos trabalhos.

Os principais resultados dos seis estudos que buscaram as determinantes da política de dividendos são os que indicam as variáveis de maior influência na distribuição, quais sejam: lucro líquido, fluxo de caixa, porte da empresa e menor endividamento. Os fatores que mais influenciam negativamente o pagamento de dividendos e JCP são oportunidades de investimento e maior concentração de propriedade nas mãos do acionista controlador.

Por fim, diante da relevância do tema e da carência de estudos nessa área, sugere-se a realização de estudos explorando mais a realidade brasileira dos JCP e seu diferente tratamento tributário conforme o tipo de investidor (pessoa física, jurídica, brasileira, estrangeira), o fato de os dividendos serem isentos a partir de 1996, bem como estudos visando a identificar como é definida a política de dividendos e qual percentual do lucro é distribuído em contraposição ao percentual retido.

\section{REFERÊNCIAS}

BELlATO, L. L. N; SILVEIRA, A. D. M; SAVOIA, J. R. F. Influência da estrutura de propriedade sobre a taxa de pagamento de dividendos das companhias abertas brasileiras.
In: ENCONTRO NACIONAL DA ASSOCIAÇÃO NACIONAL DOS PROGRAMAS DE PÓS-GRADUAÇÃO EM ADMINISTRAÇÃO, 30, 2006, Salvador. Anais eletrônicos. Salvador: ANPAD, 2006. Disponível em: http://www.anpad.org.br/ enanpad/2006/dwn/enanpad2006-ficd-2274.pdf. Acesso em 21.10.2010.

BREAlEY, R. A; MYERS, S. C. Princípios de finanças empresariais. 3. ed. Lisboa: McGraw-Hill de Portugal, 1992.

BRENNAN, M. Taxes: market valuation and corporate financial policy. National Tax Journal, v. 23, n. 4, p. 417427, 1970.

BRITO, R.D; SILVA, J. C. G. Testando as previsões de trade-off e pecking order sobre dividendos e dívida no Brasil. Estudos Econômicos, São Paulo, v. 35, n. 1, p. 37-79, 2005.

BRITO, R. D; LIMA, M. R; SILVA, J. C. O crescimento da remuneração direta aos acionistas no Brasil: economia de impostos ou mudança de característica das firmas? Brazilian Business Review, v. 6, n. 1, p. 62-81, 2009.

BUENO, A. F. Os dividendos como estratégias de investimentos em ações. Revista de Contabilidade \& Finanças, São Paulo, v. 13, n. 28, p. 39-55, 2002.

CASTRO, M. L; FREIRE, H. V. L. A relação entre lucros anormais e dividendos: um estudo empírico das empresas com ações negociadas na Bovespa. In: Congresso USP de Controladoria e Contabilidade, 5, 2005, São Paulo. Anais eletrônicos. São Paulo: FEA-USP, 2005. Disponível em: www.congressousp.fipecafi.org/artigos52005/434.pdfsimilares. Acesso em 6.10.2010.

CORREIA, L. F; AMARAL, H. F. O impacto da política de dividendos sobre a rentabilidade de títulos negociados na Bovespa de 1994 a 2000. In: ENCONTRO NACIONAL DA ASSOCIAÇÃO NACIONAL DOS PROGRAMAS DE PÓS-GRADUAÇÃO EM ADMINISTRAÇÃO, 26, 2002, Salvador. Anais eletrônicos. Salvador: ANPAD, 2002. Disponível em: http://www.anpad.org.br/trabalho_popup.php?cod_edicao_trabalho=2510. Acesso em 21.10.2010.

CORSO, R. M; KASSAI, J. R; LIMA, G. A. S. F. Distribuição de dividendos e juros sobre capital próprio versus retorno das ações. In: Congresso USP de Controladoria e Contabilidade, 10, 2010. São Paulo. Anais eletrônicos. São Paulo: USP, 2010. Disponível em: www.congressousp.fipecafi.org/ artigos102010/141.pdf . Acesso em 6.10.2010. 
CUNHA, M. V. Os periódicos em ciência da informação: uma análise bibliométrica. Ci. Inf., v. 14, n. 1, p. 37-45, 1985.

DECOURT, R. F; PROCIANOY, J. L. O processo decisório da distribuição de lucros das empresas listadas na Bovespa. In: ENCONTRO BRASILEIRO DE FINANÇAS, 9, 2009, São Leopoldo. Anais eletrônicos. São Leopoldo, 2009. Disponível em: http://www.sbfin.org.br/site/Encontros/2009. Acesso em 10.10.2010.

DECOURT, R. F; PROCIANOY, J. L; PIETRO NETO, J. As variações nas distribuições dos proventos em dinheiro sinalizam variações nos lucros futuros? In: ENCONTRO NACIONAL DA ASSOCIAÇÃO NACIONAL DOS PROGRAMAS DE PÓS-GRADUAÇÃO EM ADMINISTRAÇÃO, 31, 2007, Rio de Janeiro. Anais eletrônicos. Rio de Janeiro: ANPAD, 2007. Disponível em: http://www.anpad.org.br/trabalho_popup. php?cod_edicao_trabalho=7411. Acesso em 19.11.2010.

ELTON, E. J; GRUBER, M. J. Marginal stockholder tax rates and the clientele effect. The Review of Economics and Statistics, v. 52, n. 1, p. 68-74, 1970.

FAMA, E.; FRENCH, K. Testing trade-off and pecking order predictions about dividends and debt. The Review of Financial Studies. v. 15, n. 1, p. 1-33, 2002.

FERREIRA JUNIOR, W. O; NAKAMURA, W. T; MARTIN, D. M. L. Evidências empíricas dos fatores determinantes das políticas de dividendos das firmas listadas na Bolsa de Valores de São Paulo. In: ENCONTRO BRASILEIRO DE FINANÇAS, 7, 2007, São Paulo. Anais eletrônicos. São Paulo: SBFIN, 2007. Disponível em: http://www.sbfin.org.br/site/ Encontros/2007. Acesso em 10.10.2010.

FIGUEIREDO, A. C. O conteúdo informativo de dividendos: evidências no Brasil. In: ENCONTRO BRASILEIRO DE FINANÇAS, 2, 2002, Rio de Janeiro. Anais eletrônicos. Rio de Janeiro: SBFIN, 2002. Disponível em: http://www.sbfin. org.br/site/Encontros/2002. Acesso em 9.10.2010.

FIORATI, A. R. S; GARCIA S. G; TAMBOSI FILHO, E. Dividendos e juros sobre capital próprio: sinalização de lucratividade futura? Um estudo no mercado brasileiro 1999-2004. In: ENCONTRO NACIONAL DA ASSOCIAÇÃO NACIONAL DOS PROGRAMAS DE PÓS-GRADUAÇÃO EM ADMINISTRAÇÃO, 31, 2007, Rio de Janeiro. Anais eletrônicos. Rio de Janeiro: ANPAD, 2007. Disponível em: http://www.anpad. org.br/trabalho_popup.php?cod_edicao_trabalho=7395. Acesso em 19.11.2010.
FIRMINO, A. L.; GAMA, A; BRUNI, A. L; FAMÁ, R. O anúncio da distribuição de dividendos e seu efeito sobre o preço das ações. In: Congresso USP de Controladoria e Contabilidade, 3, 2003, São Paulo. Anais. São Paulo, 2003.

FIRMinO, A. L. G; SANTOS, A. G. Q; MATSumoto, A. S. Dividendos interessam? Uma constatação empírica recente sobre a relevância da política de dividendos na bolsa de valores de São Paulo (1996 a 2002). In: ENCONTRO BRASILEIRO DE FINANÇAS, 4, 2004, Rio de Janeiro. Anais eletrônicos. Rio de Janeiro, 2004. Disponível em: http://www.sbfin.org.br/site/Encontros/2004. Acesso em 9.10.2010.

FREIRE, H. V. L; LIMA, I. S. O comportamento dos dividendos versus lucros anormais. In: ENCONTRO NACIONAL DA ASSOCIAÇÃO NACIONAL DOS PROGRAMAS DE PÓS-GRADUAÇÃO EM ADMINISTRAÇÃO, 27, 2005, Brasília. Anais eletrônicos. Brasília: ANPAD, 2005. Disponível em: http://www.anpad.org.br/trabalho_popup.php?cod_edicao_trabalho=1696. Acesso em 21.10.2010.

FREIRE, H. V. L; ZATTA, F. N; DALMÁCIO, F. Z; LOUZADA, L. C; NOSSA, V. Dividendos e lucros anormais: um estudo nas empresas listadas na Bovespa. Revista de Contabilidade E Finanças, v. 16, n. 39, p. 47-67, 2005.

FREITAS, A; COSTA, J. F. Política de dividendos no Brasil: resultados preliminares. In: ENCONTRO NACIONAL DA ASSOCIAÇÃO NACIONAL DOS PROGRAMAS DE PÓS-GRADUAÇÃO EM ADMINISTRAÇÃO, 14, 1990, Florianópolis. Anais. Florianópolis: ANPAD, 1990.

FUTUEMA, M. S; BASSO, L. F. C; KAYO, E. K. Estrutura de capital, dividendos e juros sobre capital próprio: testes no Brasil. Revista de Contabilidade E Finanças, v. 20, n. 49, p. 44-62, 2009.

GONZAGA, R. P; COSTA, F. M. A relação entre o conservadorismo contábil e os conflitos entre acionistas controladores e minoritários sobre a política de dividendos nas empresas brasileiras listadas na Bovespa. Revista de Contabilidade E Finanças, v. 20, n. 50, p. 95-109, 2009.

GORDON, M. J. Dividends, earnings, and stock prices. The Review of Economics and Statistics, v. 41, n. 2, p. 99105, 1959.

HARRIS, M; RAVIV, A. The theory of capital structure. Journal of Finance, v. 46, n. 1, p. 297-355, 1991. 
HEINEBERG, R; PROCIANOY, J. L. Aspectos determinantes do pagamento de proventos em dinheiro das empresas com ações negociadas na Bovespa. In: ENCONTRO NACIONAL DA ASSOCIAÇÃO NACIONAL DOS PROGRAMAS DE PÓS-GRADUAÇÃO EM ADMINISTRAÇÃO, 27, 2003, Atibaia. Anais. Atibaia: ANPAD, 2003.

IQUIAPAZA, R. A; BARBOSA, F. V; BRESSAN, A. A. Dividendos: plano real, imposto de renda e sinalização nas empresas listadas na Bovespa: 1986 a 2003. In: ENCONTRO BRASILEIRO DE FINANÇAS, 5, 2005, São Paulo. Anais eletrônicos. São Paulo: SBFIN, 2005. Disponível em: http://www.sbfin.org.br/site/Encontros/2005. Acesso em 27.07.2011.

IQUIAPAZA, R. A; LAMOUNIER, W. M; AMARAL, H. F. Assimetria de informações e pagamento de proventos em dinheiro na Bovespa. In: ENCONTRO NACIONAL DA ASSOCIAÇÃO NACIONAL DOS PROGRAMAS DE PÓS-GRADUAÇÃO EM ADMINISTRAÇÃO, 30, 2006, Salvador. Anais eletrônicos. Salvador: ANPAD, 2006. Disponível em: www. anpad.org.br/enanpad/2006/dwn/enanpad2006-ficd-1472. pdf. Acesso em 8.10.2010.

JENSEN, M; MECKLING, W. Theory of the firm: managerial behavior, agency costs and ownership structure. Journal of Financial Economics, v. 3, n. 4, p. 305-360, 1976.

KURONUMA, A. M; LUCCHESI, E. P; FAMÁ, R. Retornos anormais acumulados no período pós pagamento de dividendos: um estudo empírico no mercado brasileiro. In: Congresso USP de Controladoria e Contabilidade, 4, 2004, São Paulo. Anais eletrônicos. São Paulo: USP, 2004. Disponível em: http://www.congressousp.fipecafi.org. Acesso em 16.9.2010.

LINTNER, J. Distribution of incomes of corporations among dividends, retained earnings and taxes. American Economic Review, v. 46, n. 2, p. 97-113, 1956.

LITZENBERGER, R. H; RAMASWAMY, K. The effect of personal taxes and dividends on capital asset prices: theory and empirical evidence. Journal of Financial Economics, v. 7, n. 2, p. 163-195, 1979.

LOSS, L; SARLO NETO, A. O inter-relacionamento entre políticas de dividendos e de investimentos: um estudo aplicado às companhias brasileiras negociadas na Bovespa. Revista Contabilidade E Finanças, São Paulo, v. 17, n. 40, p. 52-66, 2006.
MILLER, M. H; MODIGLIANI, F. Dividend policy, growth and the valuation of shares. Journal of Business, v. 34, n. 4, p. 411-433, 1961.

MOTA, D. C; EID JUNIOR, W. Dividendos, juros sobre capital próprio e recompra de ações: um estudo empírico sobre a política de distribuição no Brasil. In: ENCONTRO NACIONAL DA ASSOCIAÇÃO NACIONAL DOS PROGRAMAS DE PÓS-GRADUAÇÃO EM ADMINISTRAÇÃO, 34, 2010, Rio de Janeiro. Anais eletrônicos. Rio de Janeiro: ANPAD, 2010. Disponível em: http://www.anpad.org.br. Acesso em 7.10.2010.

NOSSA, S. N; NOSSA, V; TEIXEIRA, A. J. C. As empresas que distribuem dividendos são mais eficientes? In: Congresso USP de Controladoria e Contabilidade, 7, 2007, São Paulo. Anais eletrônicos. São Paulo: USP, 2007. Disponível em: http://www.congressousp.fipecafi.org. Acesso em 6.10.2010.

NOVIS NETO, J. A; SAITO, R. Pagamentos de dividendos e persistência de retornos anormais das ações: evidência do mercado brasileiro. RAUSP-Revista de Administração, v. 38, n. 2, p. 135-143, 2003.

PAIVA, J. W. M; LIMA, A. V. A influência da tributação e dos juros sobre o capital próprio na política de dividendos das companhias brasileiras. In: ENCONTRO BRASILEIRO DE FINANÇAS, 1, 2010. Anais eletrônicos. SBFIN, 2001. Disponível em: http://www.sbfin.org.br. Acesso em 9.10.2010.

PEROBELLI, F. F. C; SANTOS, A. B. Vale a pena investir em ações high yield? Novas evidências sobre o efeito do pagamento de dividendos e juros sobre capital próprio sobre os preços das ações brasileiras. In: ENCONTRO NACIONAL DA ASSOCIAÇÃO NACIONAL DOS PROGRAMAS DE PÓS-GRADUAÇÃO EM ADMINISTRAÇÃO, 30, 2006, Salvador. Anais eletrônicos. Salvador: ANPAD, 2006. Disponível em: http://www.anpad.org.br/trabalho_popup.php?cod_edicao_trabalho=5764. Acesso em 8.10.2010.

PEROBElli, F. F. C; ZANINI, A; SANTOS, A. B. dos. Pagamento de proventos versus preços de ações maduras e em expansão segundo Kohonen Maps. RAE-Revista de Administração de Empresas, v. 49, n. 2, p. 132-146, 2009.

POLI, B. T. C; PROCIANOY, J. L. A resposta das empresas à modificação tributária de 1990: dividendos x ganho de capital. In: ENCONTRO NACIONAL DA ASSOCIAÇÃO NACIONAL DOS PROGRAMAS DE PÓS-GRADUAÇÃO EM 
ADMINISTRAÇÃO, 18, 1994, Curitiba. Anais. Curitiba: ANPAD, 1994.

PROCIANOY, J. L. A política de dividendos e o preço das ações. In: VARGA, G; LEAL, R. P. C. (Orgs). Gestão de investimentos e fundos. Rio de Janeiro: Financial, 2006. p. 39-164.

PROCIANOY, J. L. Dividendos e tributação: o que aconteceu após 1988-1989. RAUSP-Revista de Administração, v. 31, n. 2, p. 7-18, 1996.

PROCIANOY, J. L; KWITKO, L. C. Ações de empresas brasileiras e suas ADRs: uma nota sobre datas ex dividend. Revista Brasileira de Economia, v. 61, n. 1, p. 111-124, 2007.

PROCIANOY, J. L; VERDI, R. S. O efeito clientela no mercado brasileiro: será que os investidores são irracionais? Revista Brasileira de Finanças, v. 1, n. 2, p. 217-242, 2003.

PROCIANOY, J. L; VERDI, R. S. Clientela em dividendos, novos elementos e novas questões: o caso brasileiro. $R A E-$ -eletrônica, v. 8, n. 1, art. 1, 2009. Disponível em: http:// www.rae.com.br/eletronica. Acesso em 25.9.2010.

RAMOS, C. F. A influência da tributação sobre o retorno das ações em função da distribuição de dividendos feitas pelas companhias negociadas na Bovespa: um estudo do mercado brasileiro. In: ENANPAD, 1997. Anais eletrônicos. ANPAD, 1997. Disponível em: http://www.anpad.org.br. Acesso em 21.10.2010.

SANTOS, A. G. Q; FIRMINO, A. L. G; BRUNI, A; MATSUMOTO, A. S. A influência da tributação sobre dividendos e juros sobre o capital próprio no comportamento dos preços das ações: uma análise empírica na Bovespa. In: ENCONTRO NACIONAL DA ASSOCIAÇÃO NACIONAL DOS PROGRAMAS DE PÓS-GRADUAÇÃO EM ADMINISTRAÇÃO, 28, 2004, Curitiba. Anais. Curitiba: ANPAD, 2004. Disponível em: http://www.anpad.org.br. Acesso em 21.10.2010.

SILVA, A. L. C. Governança corporativa, valor, alavancagem e política de dividendos das empresas brasileiras. RAUSP-Revista de Administração, v. 39, n. 4, p. 348-361, 2004.

SILVA, S. M. B. The influence of agency costs on the dividend policy of brazilian listed companies. In: ENCONTRO NACIONAL DA ASSOCIAÇÃO NACIONAL DOS PROGRAMAS DE PÓS-GRADUAÇÃO EM ADMINISTRAÇÃO, 27, 2003, Atibaia. Anais. Atibaia: ANPAD, 2003. Disponível em: http://www.anpad.org.br. Acesso em 31.7.2011. 